\title{
Taeyeumjoweetang Affects Body Weight and Obesity-related Genes in Mice
}

\section{Si-Woo Lee ${ }^{1}$, Jong-Hyang Yoo', Su-Kyung Lee ${ }^{2}$, Kyung-Soo Keum ${ }^{3}$, Do-Gon Ryu ${ }^{4}$ and Kang-Beom Kwon ${ }^{4}$}

${ }^{1}$ Korea Institute of Oriental Medicine, Daejeon, South Korea, ${ }^{2}$ Department of Rehabilitation, ${ }^{3}$ Department of Classics and ${ }^{4}$ Department of Physiology, College of Oriental Medicine, Wonkwang University, Iksan, Chonbuk, Republic of Korea

Taeyeumjoweetang (TYJWT) is a herbal medication that was mentioned in Jema Lee's Donguisusebowon, which is a book about Sasang constitutional medicine. Tae-eumnis, one of the four constitutions, tend to suffer from metabolic diseases such as obesity and diabetes. It is widely used to treat the digestive problems and obesity of Tae-eumins. We divided mice that were fed a normal diet for 48 days into control, TYJWT $250 \mathrm{mg} \mathrm{kg}^{-1}$ and TYJWT $500 \mathrm{mg} \mathrm{kg}^{-1}$ groups. After carrying out the experiments, the serum levels of leptin, adiponectin, ghrelin and resistin were measured. The results showed that TYJWT significantly reduced the weights of mice that were fed a normal diet, and that this was due to a decrease in food intake. Also, the two TYJWT groups had lower serum levels of leptin compared to the control group, and the ghrelin levels were proportionately increased by the dosage of TYJWT given. These results show that TYJWT has obesity-suppressing effects similar to those previously reported using high fat diets. In addition, these results also provide evidence that TYJWT has anti-obesity effects.

Keywords: ghrelin - leptin - Sasang constitutional medicine

\section{Introduction}

Taeyeumjoweetang (TWJWT) was first mentioned by Jema Lee (1837-1900) in Donguisusebowon as a herbal medication consisting of eight herbs, which is used to treat 'exterior-cold disease by cold in the esophagus' of Tae-eumin (1). To date, research on the anti-obesity effects of TYJWT showed that it suppressed the weights and serum lipid profiles of obese mice induced by a highfat diet (2), its herbal acupuncture form improved the high-fat-diet-induced lipid profiles of serum and the liver (3) and that it suppressed leptin gene expression in obese mice (4).

For reprints and all correspondence: Prof. Kang-Beom Kwon, Department of Physiology, College of Oriental Medicine, Wonkwang University, 344-2 Shinyoung-dong, Iksan, Chonbuk 570-749, Republic of Korea. Tel: +82-63-850-6917; Fax: +82-63-842-3138;

E-mail: desson@wonkwang.ac.kr
Obesity is a chronic metabolic disorder caused by an imbalance between energy intake and usage, and is characterized by weight gain due to an increase in body fat and serum lipid content $(5,6)$. Recent research shows that several substances are secreted by adipose cells that either cause or improve obesity. Among these, leptin and resistin are important factors that control weight, although their exact roles have not yet been defined (7). Ghrelin is secreted by the stomach (8) and its synthesis and secretion are primarily controlled by changes in body energy. Its secretion is increased when the energy level is low and secretion decreases when the energy level is high (9). Ghrelin expression is also controlled by leptin (10).

To date, research into the anti-obesity effects of TYJWT have used obese animal models that were induced by a high-fat diet (2-4). TYJWT has been widely used for treatment of Tae-eumins' obesity in Korea. In order to closely approach the clinical 
condition, we explored the effects of TYJWT on mice that were fed a normal diet. For 48 days, we measured the weights and food intakes of mice that were given 250 and $500 \mathrm{mg} \mathrm{kg}^{-1}$ doses of TYJWT, as well as the levels of serum leptin, resistin, ghrelin and adiponectin.

\section{Methods}

\section{Test Animals}

We purchased $30 \mathrm{C} 57 \mathrm{BL} / 6 \mathrm{~J}$ male mice $(20-25 \mathrm{~g})$ that were 3 weeks old from Central Lab. Animal Inc. The mice were adapted to the test environment by being fed standard experiment diet for 1 week. The mice were raised in a controlled environment (temperature at $20{ }^{\circ} \mathrm{C}, 50 \%$ humidity, light cycle from $06: 00$ to $18: 00$ hours and dark cycle from 18:00 to 06:00 hours), and during the experiment they were allowed to drink water freely. All these procedures involving the use of animals have been conducted in agreement with NIH Guidelines and approved by the Animal Use and Care Committee of Wonkwang University.

\section{TYJWT Extraction Method}

After purchasing TYJWT (Table 1) from Wonkwang Oriental Medical Hospital, it was certified by the Department of Herbology, College of Oriental Medicine, Wonkwang University before use. TYJWT $(200 \mathrm{~g})$ was placed in a round bottom flask with 1.81 of triple distilled water. After attaching a freezer, it was boiled for $3 \mathrm{~h}$, centrifuged at $3000 \mathrm{rpm}$ for $20 \mathrm{~min}$, decompressed and concentrated using a rotating vacuum concentrator. Using a freeze drying machine, $31.3 \mathrm{~g}$ of powder was obtained. This was stored at $-70^{\circ} \mathrm{C}$ until used in experiments.

\section{Test Groups}

The mice were divided into three groups and were fed for 48 days as follows. The control group was fed a normal

Table 1. Composition of TYJWT

\begin{tabular}{llc}
\hline Herbal name & Scientific name & Amount $(\mathrm{g})$ \\
\hline 薏荝仁 & Semen Coicis & 11.25 \\
乾栗 & Castanea Mollisima & 11.25 \\
蘿䔰子 & Semen Raphani & 7.5 \\
五味子 & Fructus Schizandrae & 3.75 \\
麥門冬 & Radix Ophiopogonis & 3.75 \\
石菖蒲 & Rhizoma Acori Graminei & 3.75 \\
桔梗 & Radix Platycodi & 3.75 \\
麻黄 & Heraba Ephedrae & 3.75 \\
& Total amount & 48.75 \\
\hline
\end{tabular}

diet and was given saline twice daily. The TYJWT groups were given oral doses of 250 and $500 \mathrm{mg} \mathrm{kg}^{-1}$ twice daily, at 09:00 and 21:00 hours. Weights and food intakes were measured every 4 days. After this period, the mice were decapitated, serum was separated, and separated epididymal fat and stomach were stored at $-70^{\circ} \mathrm{C}$ until assayed.

\section{ELISA}

Serum concentrations for leptin, adiponectin, ghrelin and resistin were measured using ELISA kits (Roche Diagnostics, CA, USA) according to the manufacturer's protocols.

\section{RNA Extraction}

The extraction of total RNA from the stomach and fat tissues used Trizol reagent (Life Technologies, UK) according to the manufacturer's protocols. Tissue $(100 \mathrm{mg})$ was cut into pieces, dissolved in $500 \mu \mathrm{l}$ RNAzol B, $50 \mu$ l chloroform was added, and the reaction was run for $5 \mathrm{~min}$ on ice. After the reaction, samples were centrifuged at $15700 \mathrm{~g}$ at $4^{\circ} \mathrm{C}$ for $20 \mathrm{~min}$, and then the upper layer was put in a new tube. An equal volume of isopropanol was added to the upper layer, and the reaction was run for $30 \mathrm{~min}$. After the reaction, samples were centrifuged at $15700 \mathrm{~g}$ at $4^{\circ} \mathrm{C}$ for $20 \mathrm{~min}$, and then the sediments were cleansed with $80 \% \mathrm{EtOH}$. The cleansed RNA was dried, melted with 20 of DEPCtreated water and the optical density was quantified using a spectrophotometer.

\section{Real-Time Reverse Transcription Polymerase Chain Reaction}

Reverse transcription reactions used 3-5 $3 \mathrm{~g}$ total RNA and reverse transcriptase (MMLV; Invitrogen, Carlsbad, $\mathrm{CA})$ according to the manufacturer's protocol. The reaction used a reaction solution of total RNA $(3-5 \mu \mathrm{g})$, oligo d (T) 12-18 (1 $\mathrm{gg}), 2 \mu \mathrm{dNTP}(10 \mathrm{mM})$, MMLV reverse transcriptase (200 U), DTT $(10 \mathrm{mM})$, RNase inhibitor $(1 \mu \mathrm{l}$; Promega, USA) and a $20 \mu \mathrm{l}$ buffer solution ( $50 \mathrm{mM}$ Tris-Cl, pH 8.3, $75 \mathrm{mM} \mathrm{KCl}, 3 \mathrm{mM} \mathrm{MgCl}_{2}$ ) at $42^{\circ} \mathrm{C}$ for $60 \mathrm{~min}$, after which cDNA was synthesized. Real-time reverse transcription polymerase chain reaction was done by mixing cDNA (diluted 10 times) with $2 \times$ SYBR-Green buffer solution (Roche Diagnostics Ltd, UK), which contained reverse transcription enzymes, using a LightCycler rapid thermal cycler system (Roche). In summary, after letting the reaction mixture react at $95^{\circ} \mathrm{C}$ for $10 \mathrm{~min}, 45$ cycles of denaturation $\left(95^{\circ} \mathrm{C} 10 \mathrm{~s}\right)$, annealing $\left(58^{\circ} \mathrm{C}\right.$ for leptin, ghrelin or $60^{\circ} \mathrm{C}$ for $\beta$-actin, $5 \mathrm{~s})$ and elongation $\left(72^{\circ} \mathrm{C} 10 \mathrm{~s}\right)$ were done. The expressed leptin and ghrelin concentrations were calculated relative to the amount of $\beta$-actin using 
Table 2. Sequences and accession numbers for primers used for realtime PCR

\begin{tabular}{llc}
\hline Gene & Sequence for Primers $\left(5^{\prime} \rightarrow 3^{\prime}\right)$ & Accession no. \\
\hline$\beta$-Actin & $\begin{array}{l}\text { Forward: gtgctatgttgctctagact } \\
\text { Reverse: cacaggattccataccaag }\end{array}$ & NM 007393 \\
Leptin & $\begin{array}{l}\text { Forward: caggatcaatgacatttcacaca } \\
\text { Reverse: gctggtgaggacctgttgat }\end{array}$ & NM 008493 \\
Ghrelin & $\begin{array}{l}\text { Forward: ccagaggacagaggacaagc } \\
\text { Reverse: catcgaagggagcattgaac }\end{array}$ & NM 021488 \\
\hline
\end{tabular}

LightCycler System software (Roche). The primers for leptin, ghrelin and $\beta$-actin are shown in Table 2.

\section{Statistical Analysis}

Test results were expressed as mean \pm SEM. Group comparisons used a one-way ANOVA test (Microcal Origin; version6.0; Microsoft, USA), with $P<0.05$ considered statistically significant.

\section{Results}

\section{Decrease of Body Weight}

In order to explore the effects of TYJWT on weight changes of normal mice, 250 and $500 \mathrm{mg} \mathrm{kg}^{-1}$ oral doses of TYJWT were given for 48 days, and weight changes were measured every 4 days. As shown in Fig. 1, the control group mice, which were fed a normal diet, showed significant weight gains as time passed. However, the TYJWT groups showed significant weight losses compared to the control group starting at Day 36, and the weight loss effects in the $250 \mathrm{mg} \mathrm{kg}^{-1}$ group was more pronounced than the $500 \mathrm{mg} \mathrm{kg}^{-1}$ group (Fig. 1). Regarding food intake, starting at Day 36 , the TYJWT groups ate less compared to the control group (Fig. 2).

\section{Changes in Leptin and Ghrelin Expression}

In order to find a relationship between the weight loss effects of TYJWT and appetite, we examined the serum levels of leptin and ghrelin, as well as their mRNA expressions in the fat and stomach tissues (Fig. 3). The results showed that the $500 \mathrm{mg} \mathrm{kg}^{-1}$ TYJWT group secreted significantly less leptin into the bloodstream compared to the control group, and the expression of leptin mRNA in fat tissue also coincided with this result. By comparison, the levels of ghrelin secreted into the serum as well as the expression of mRNA in the stomach tissue were proportionate to the dosage of TYJWT given.

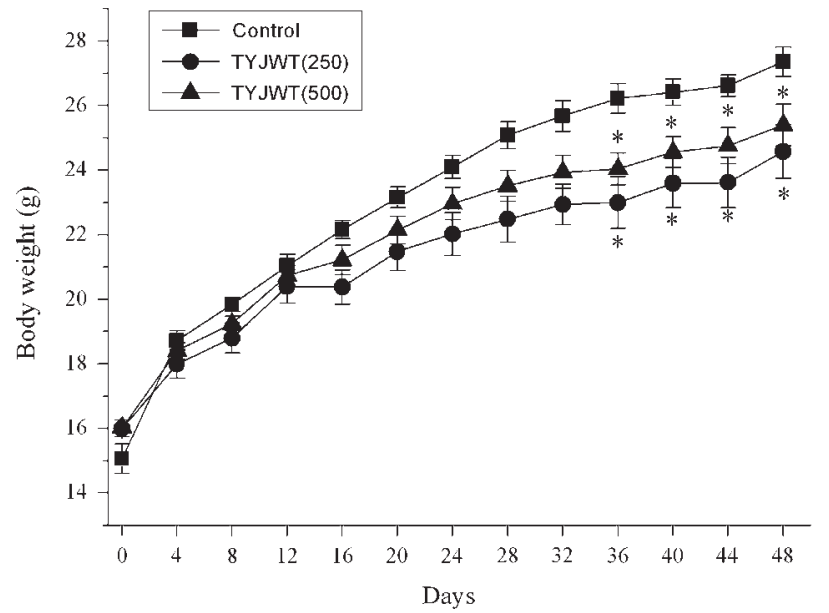

Figure 1. Effects of TYJWT on body weight changes in mice. Control: normal diet group, $n=10$; TYJWT (250): normal diet $+250 \mathrm{mg} \mathrm{kg}^{-1}$ TYJWT extract; TYJWT (500): normal diet $+500 \mathrm{mg} \mathrm{kg}^{-1}$ TYJWT extracts. Values are mean \pm SEM. ${ }^{*} P<0.05$ versus control.

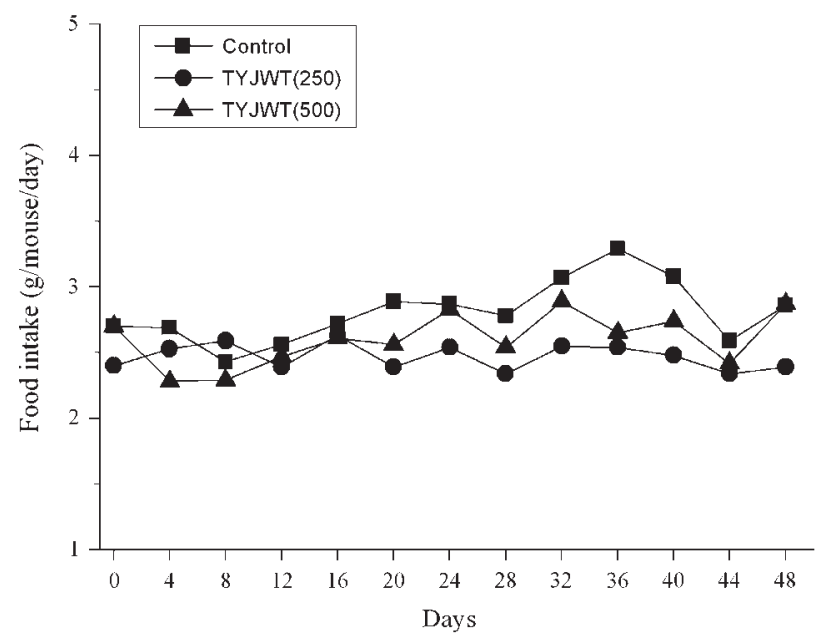

Figure 2. Effects of TYJWT on food intake in mice.

\section{Reduction in Secretions of Adiponectin and Resistin}

In order to examine a weight loss mechanism for TYJWT, the levels of adiponectin and resistin secreted into the serum were measured (Fig. 4). The adiponectin levels of the two TYJWT groups were not significantly different from one another, but TYJWT reduced the amounts of resistin secreted into the bloodstream in a dose-dependent manner.

\section{Discussion}

Obesity is a metabolic disorder caused by excess energy intake relative to energy usage and is a state in which the supply of energy is so excessive that the remainder of energy accumulates in the body $(11,12)$. Because obesity 

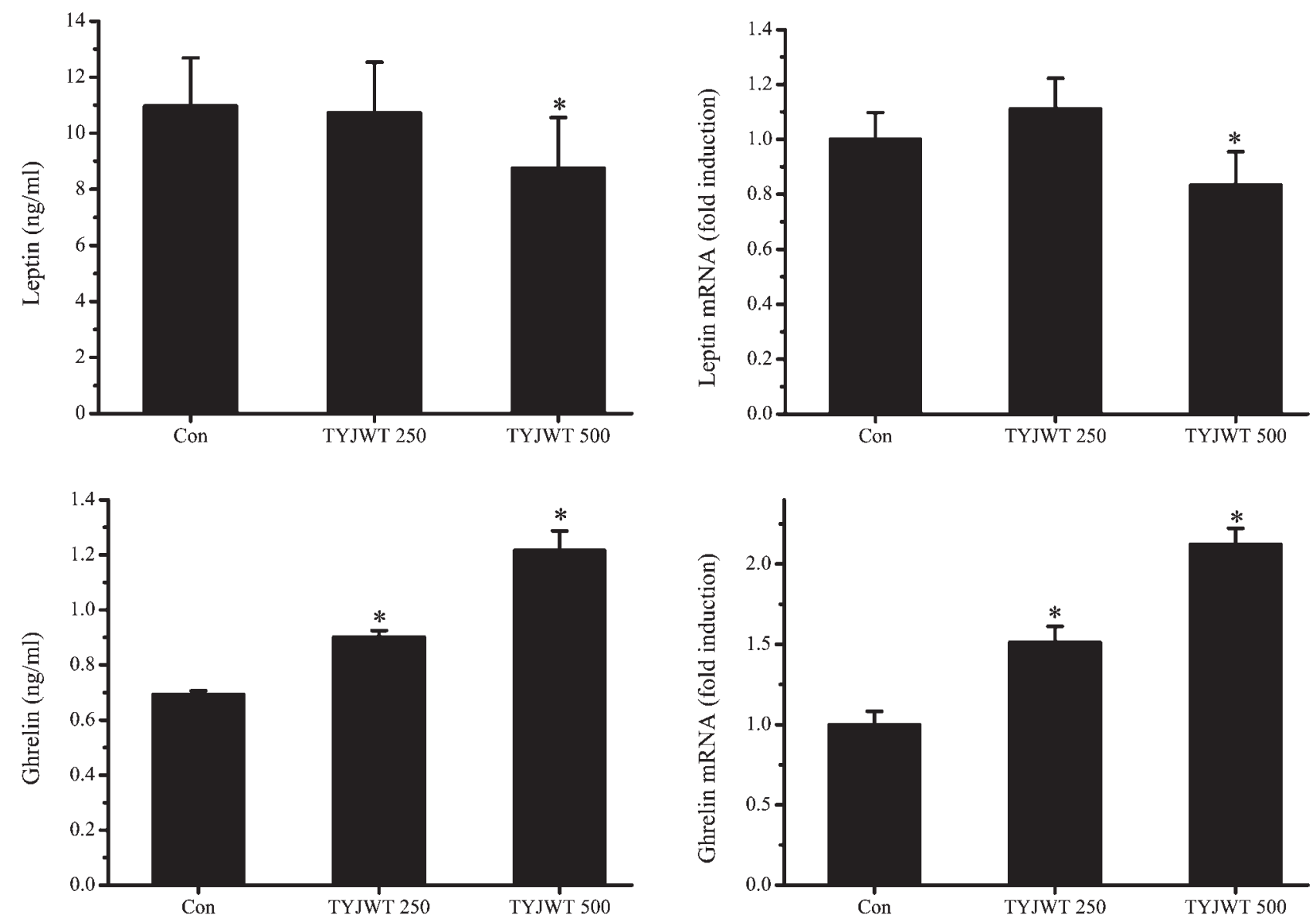

Figure 3. Effects of TYJWT on leptin and ghrelin expressions in mice. Leptin and ghrelin concentrations in plasma were measured by ELISA; mRNA levels were measured by the real-time PCR assay as described in the 'Methods' section. Values are mean \pm SEM. $* P<0.05$ versus control.

is strongly associated with depression, diabetes, hypertension, hyperlipidemia, coronary heart disease and arthritis, there have been numerous efforts to prevent and treat obesity. However, most medications used have significant side effects as well as hepatotoxicity, so their long-term use is impossible. And long-term medications that have been approved by the FDA, such as orlistat (Xenical) and sibutramine (Reductil), have been shown to suppress fat accumulation and induce weight loss, but have side effects like oily stool, physconia, undurable stool, headache, constipation, thirst, nausea, dizziness and insomnia $(13,14)$. Therefore, research into herbal medications, which have been proven to have fewer side effects than these medications, is needed.

TYJWT is the most widely used clinical anti-obesity herbal medication. Although it has been reported on its positive effects for obesity many times (2-4), its antiobesity mechanism has not yet been clarified. Tests that examined the anti-obesity effects of TYJWT have mainly used obese animal models that were induced by a high fat diet (2-4). In contrast, our research examined the effects of TYJWT on mice that were fed a normal diet. TYJWT extract significantly reduced the weight gains caused by a normal diet (Figs 1 and 2). Furthermore, TYJWT suppressed slightly fat accumulation in the epididymal fat pad (data not shown) without suppressing feed intake, which led to a decrease in the body weight gain. These results indirectly suggest that TYJWT decreases weight gain not only by reducing fat mass but also by reducing lean body mass. Therefore, further study is required to clarify the possible metabolic effect of TYJWT on lean body mass.

Generally, leptin is secreted by fat tissues and controlled by neuropeptide $\mathrm{Y}$ from the thalamus, which reduces food intake and suppresses weight gain (15). But, when its secretion is excessive, or when leptin exposure is prolonged, it accelerates lipolysis and increases energy use (16). The lower leptin concentration observed in the serum of TYJWT-treated mice could not be related to the improvement of metabolic changes, such as the lipid-lowering effect of TYJWT. Considering the current state of research into the role of leptin in obesity and obesity-related genes, more research is needed.

In contrast to the appetite-suppressing effects of leptin, ghrelin, which is secreted by the stomach, increases appetite. Ghrelin has been shown to be controlled by 

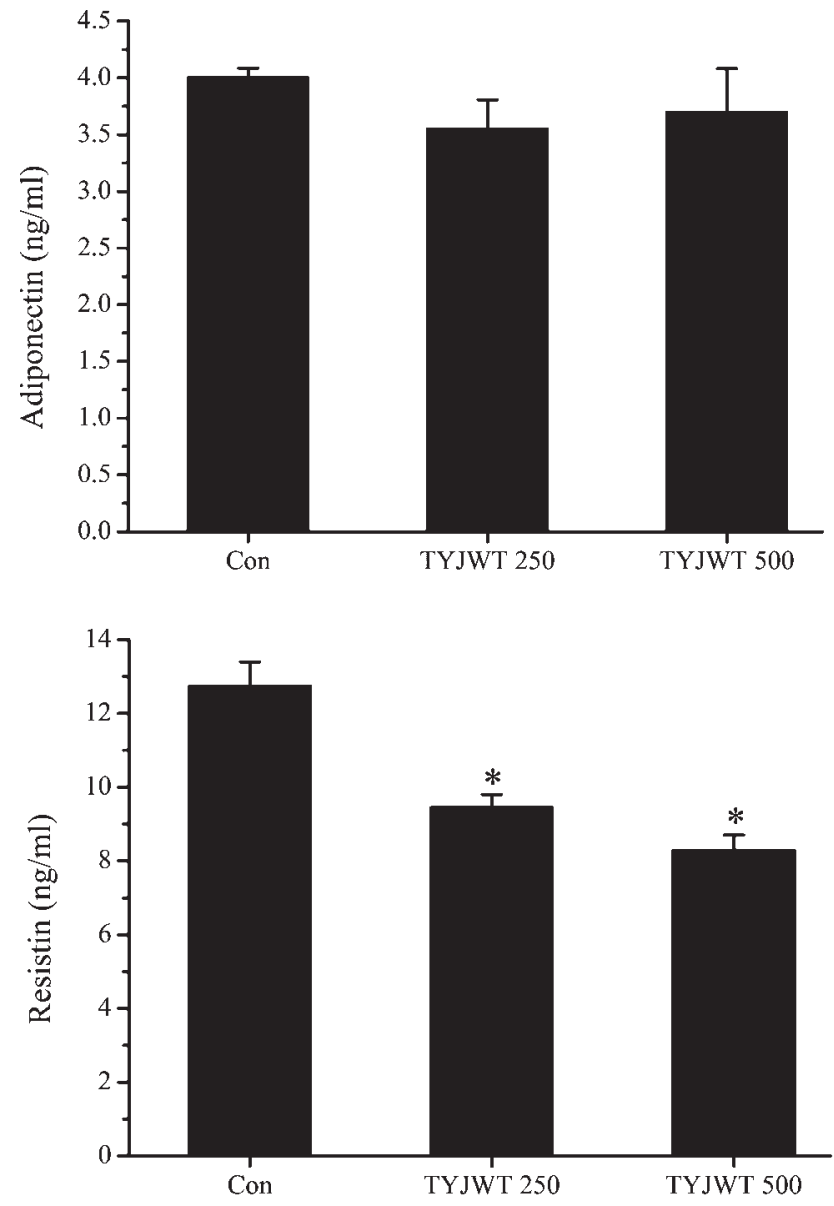

Figure 4. Effects of TYJWT on plasma adiponectin and resistin in mice. Adiponectin and resistin levels in plasma were measured by ELISA. Values are mean \pm SEM. ${ }^{*} P<0.05$ versus control.

the body's energy levels, as its levels increase during hunger and decrease when food is eaten (9). Leptin, insulin and somatostatin have been reported to be affected by the secretion of ghrelin in the stomach $(9,10,17)$. In our tests, the $500 \mathrm{mg} \mathrm{kg}^{-1}$ TYJWT group showed reduced leptin expression compared to the control group. But, the levels of ghrelin increased proportionately to the dosage of TYJWT given. According to research on the effects of leptin and ghrelin on appetite and weight $(9,17)$, TYJWT extract increased appetite and weight, yet in our tests, TYJWT extract resulted in reduced weight. According to Toshinai (18), when leptin was given to mice for 5 days, the ghrelin mRNA levels increased. However, Asakawa et al. (9) reported that leptin decreased the expression of ghrelin. Initial reports showed that leptin is secreted by fat tissues (19), but it is now known that it is also secreted from various tissues, including the stomach (20). The possibility that the leptin-reducing effect of TYJWT is due to its influence on leptin expression and secretion by other tissues besides fat tissue cannot be excluded, and further research is necessary. Also, we conclude that leptin influences the expression of ghrelin in the stomach.

Recently, fat tissue has been found not only to store fat but also to secrete adipocytokines, such as adiponectin, leptin and TNF- $\alpha$. Recent research shows that serum adiponectin levels are lower in obesity that is accompanied by type 2 diabetes (21). Resistin increases insulin resistance and fat synthesis. Thus, in resistin knockout mice, glucose intolerance was improved and fat synthesis was suppressed in the fat tissues (22). As shown in Fig. 4, TYJWT extract did not influence the serum adiponectin levels, but it did reduce the resistin levels inversely according to the dosage. We can analogize that TYJWT extract lowers weight by suppressing fat synthesis due to decreased food intake, but the lipolysis effects of TYJWT cannot be excluded.

In our tests, TYJWT reduced the weights of mice that were fed a normal diet. Along with previous results showing that TYJWT extract suppressed obesity in high-fatdiet-fed mice (2-4), these results will be a basis for the development of TYJWT as an anti-obesity medication. For the future, more detailed research into the mechanisms of TYJWT's anti-obesity effects must be done.

\section{Funding}

Korea Science and Engineering Foundation (KOSEF) grant funded by the Korea government (MEST) (Grant No. M10643020001-08N4302-00100); Korea Institute of Oriental Medicine grant funded by the Korean government (Grant No. K08020).

\section{References}

1. Lee JM. Donguisusebowon. Seoul: Daesung Books, 1993.

2. Park SS, Cho SW. Effects of Taeyeumjoweetang on loss in weight, plasma lipids and UCPI revelation of fated white rats. $J$ Korean Oriental Med 2004;25:87-97.

3. Lim YT, Lee JM. Effects of Taeyumjoweetang herbal acupuncture on plasma and liver lipid composition and antioxidative capacity in rat fed high fat diet. J Meridian Acupoint Med 2005;22:151-61.

4. Shin DJ, Kim DR, Kim SH. The effect of Taeumjowetang and Herba Ephedrae on the obese mRNA and TNF- $\alpha$ mRNA in obesity-induced rats. J Sasang Constitutional Med 2001;13:79-87.

5. Devlin MJ, Yanovski SZ, Wilson GT. Obesity: what mental health professionals need to know. Am J Psychiatry 2000;157:854-66.

6. Fujioka K. Management of obesity as a chronic disease: nonpharmacologic, pharmacologic, and surgical options. Obes Res 2002;10: $116 \mathrm{~S}-23 \mathrm{~S}$.

7. Kamohara S, Burcelin R, Halaas JL, Friedman JM, Charron MJ. Acute stimulation of glucose metabolism in mice by leptin treatment. Nature 1997;389:374-7.

8. Kojima M, Hosoda $H$, Date $Y$, Nakazato M, Matsuo H, Kangawa K. Ghrelin is a growth-hormone-releasing acylated peptide from stomach. Nature 1999;402:656-60.

9. Asakawa A, Inui A, Kaga T, Yuzuriha H, Nagata T, Ueno N, et al. Ghrelin is an appetite-stimulatory signal from stomach with structural resemblance to motilin. Gastroenterology 2004;120:337-45.

10. Lucidi P, Murdolo G, Di Loreto C, De Cicco A, Parlanti N, Fanelli $\mathrm{C}$, et al. Ghrelin is not necessary for adequate hormonal counterregulation of insulin-induced hypoglycemia. Diabetes 2002;51:2911-14. 
11. The Korean Academy of Oriental Rehabilitation Medicine. Oriental Rehabilitation Medicine. Seoul: Kuja Books, 2003.

12. Park HS. Obesity and weight control. J Fam Med 1992;13: 289-99.

13. Park YW. Evidence-based prescriptions of functional foods for weight control. J Fam Med 2003;24:409-15.

14. Park CY. The update of anti-obesity drug. J Kyung Hee University Medical Center 2002;18:77-85.

15. Bjorbaek C, Kahn BB. Leptin signaling in the central nervous system and the periphery. Recent Prog Horm Res 2004; 59:305-31.

16. Dobbins RL, Szczepaniak LS, Zhang W, McGarry JD. Chemical sympathectomy alters regulation of body weight during prolonged ICV leptin infusion. Am J Physiol Endocrinol Metab 2003;284: E778-87.

17. Ariyasu H, Takaya K, Tagami T. Stomach is a major source of circulating ghrelin, and feeding state determines plasma ghrelin-like immunoreactivity levels in humans. $J$ Clin Endocrinol Metab 2001;86:4753-8.
18. Toshinai K, Mondal MS, Nakazato M. Upregulation of ghrelin expression in the stomach upon fasting, insulin-induced hypoglycemia, and leptin administration. Biochem Biophys Res Commun $2001 ; 281: 1220-5$

19. Zhang Y, Proenca R, Maffei M, Barone M, Leopold L, Friedman JM. Positional cloning of the mouse obese gene and its human homologue. Nature 1994;372:425-32.

20. Wang MY, Zhou YT, Newgard CB, Unger RH. A novel leptin receptor isoform in rat. FEBS Lett 1996;392:87-90.

21. Hotta K, Funahashi T, Arita Y, Takahashi M, Matsuda M, Okamoto $\mathrm{Y}$, et al. Plasma concentrations of a novel, adiposespecific protein, adiponectin, in type 2 diabetic patients. Arterioscler Thromb Vasc Biol 2000;20:1595-9.

22. Kim KH, Zhao L, Moon Y, Kang C, Sul HS. Dominant inhibitory adipocyte-specific secretory factor (ADSF)/resistin enhances adipogenesis and improves insulin sensitivity. Proc Natl Acad Sci USA 2004;101:6780-5.

Received March 16, 2009; accepted July 9, 2009 


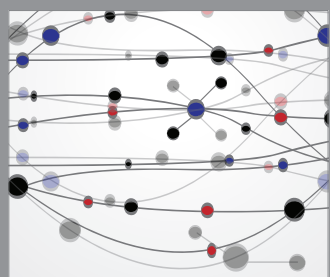

The Scientific World Journal
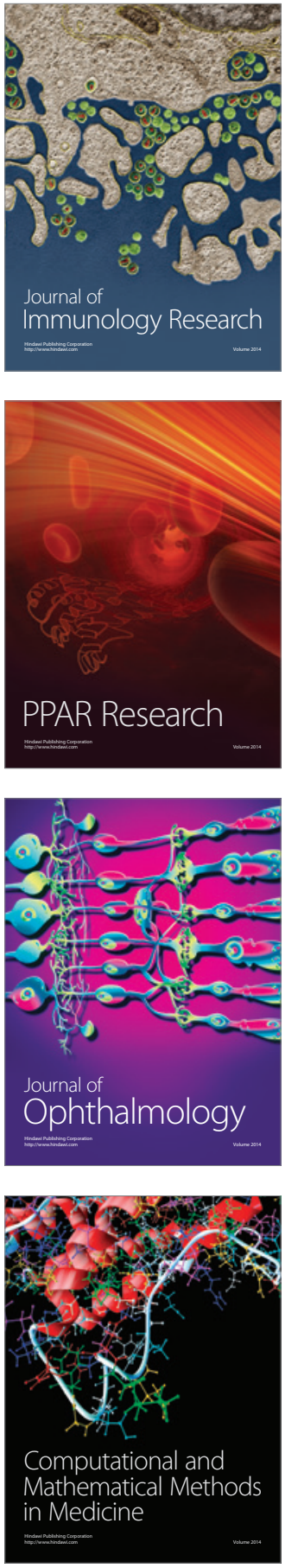

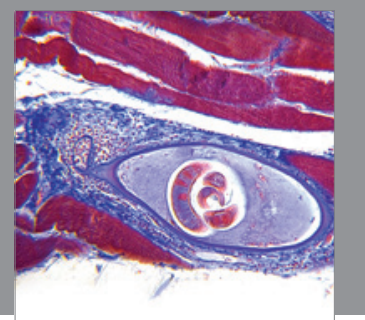

Gastroenterology

Research and Practice
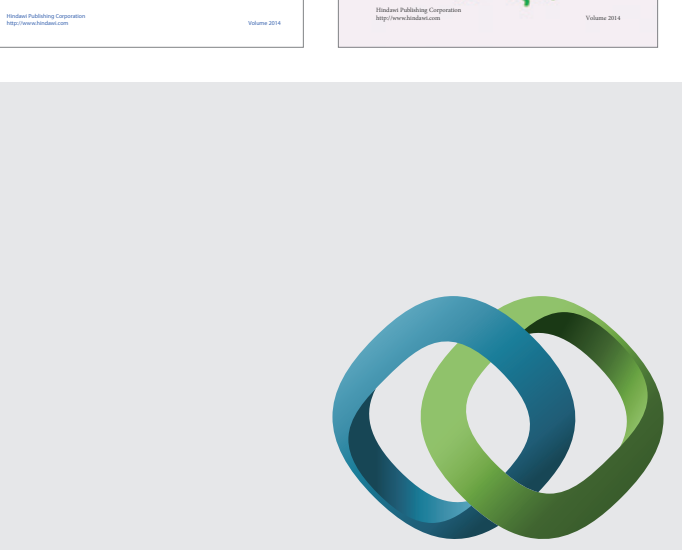

\section{Hindawi}

Submit your manuscripts at

http://www.hindawi.com
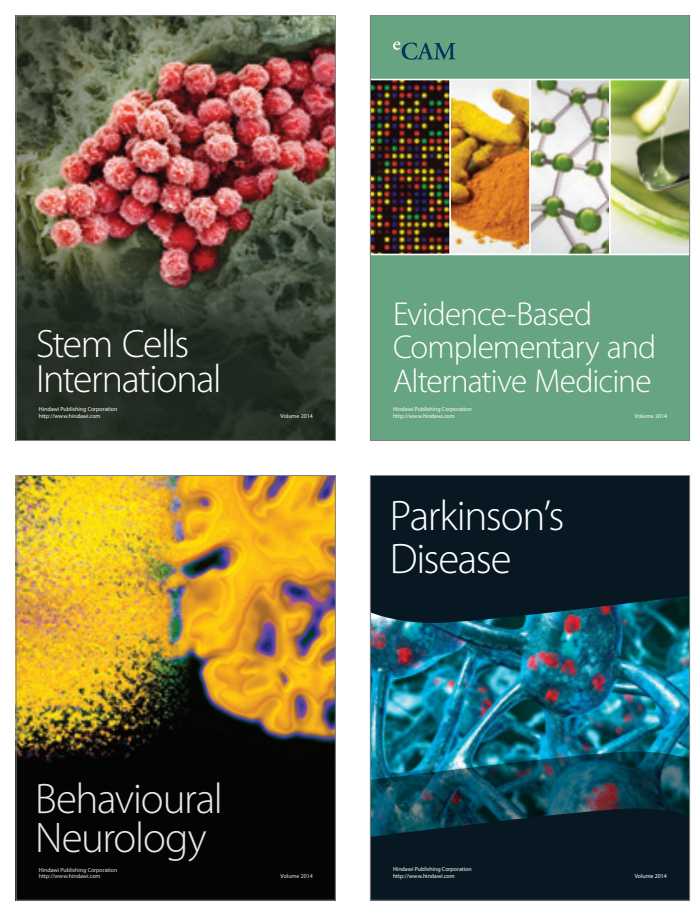

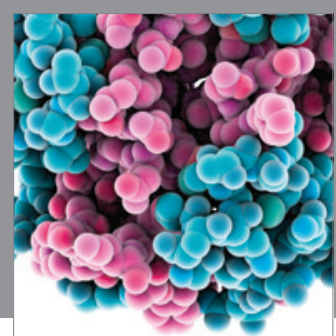

Journal of
Diabetes Research

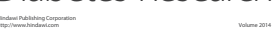

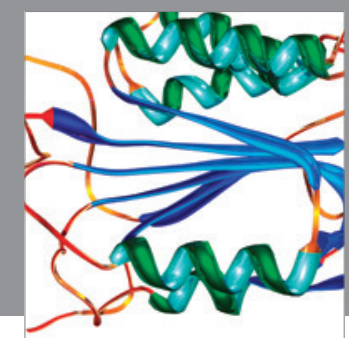

Disease Markers
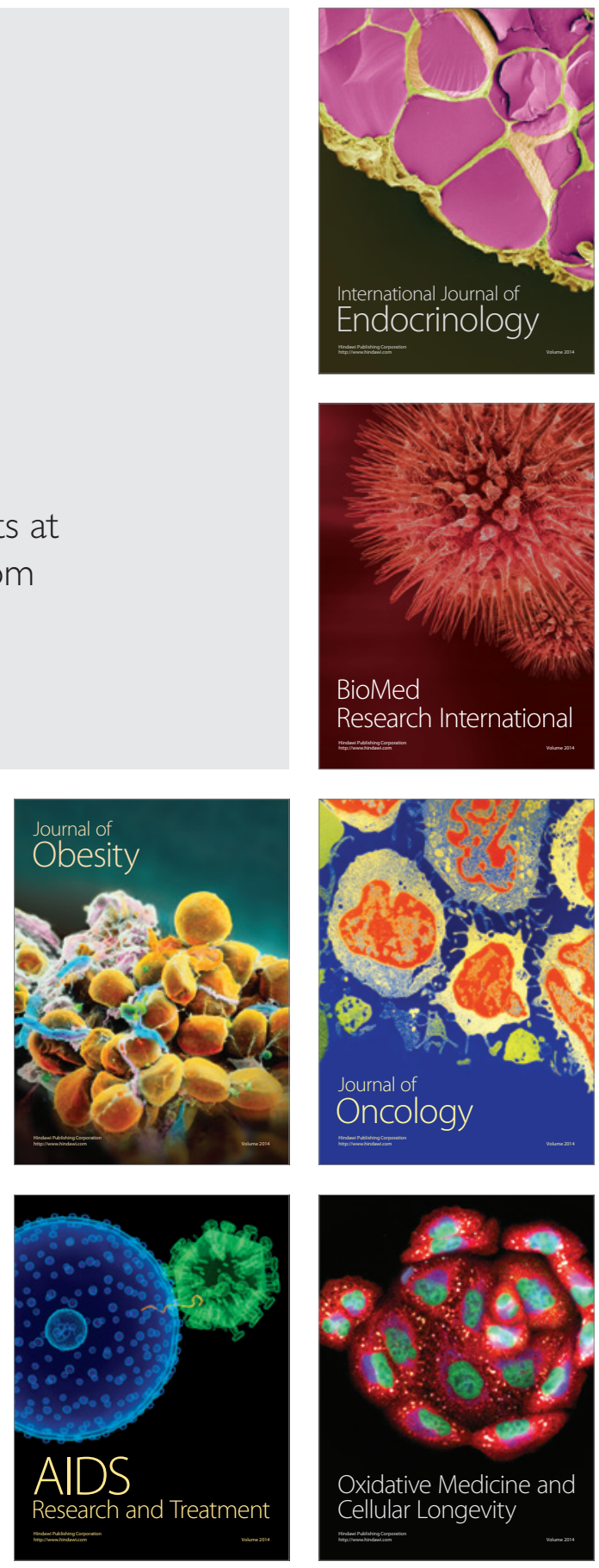